\title{
Una propuesta de antropología teológica en castillo interior de Santa Teresa de Ávila
}

\author{
Agustina Serrano Pérez \\ FACULTAD DE TEOLOGÍA \\ PONTIFICIA UNIVERSIDAD CATÓLICA DE CHILE
}

Solo Dios basta (Santa Teresa, Poesía 6)

Se busca desentrañar la sistematicidad de la antropología teológica de Santa Teresa, latente en su obra de madurez Castillo Interior. Desde el propio texto teresiano se intenta un procesamiento de los datos sobre lo humano para la formulación de un planteamiento antropológico-teológico a través del análisis de cuatro términos relevantes para la comprensión de la condición humana: razón, amor, espanto y espiritu.

Los términos razón y amor remiten a las capacidades cognoscitiva y volitiva, las que simbólicamente recapitulan todo lo humano como unidad existencial. Por otro lado, el vocablo teresiano espanto es categoría léxica y psicológica que significa, con originalidad, la postura ante el misterio; posee un componente intelectual y otro emotivo que intervienen en el proceso de interpretación de la realidad en profundidad. Es así cómo dicho término remite a una nueva noción de razón que, integrando el sentimiento, posibilita la aprehensión del misterio. De este modo, se llega al término espíritu-referido a Dios- que capacita para la experiencia de acceso al conocimiento de lo divino desde la condición humana.

Siguiendo los términos, el análisis va guiando la extracción de la latente antropología teresiana. Dicho análisis comporta un supuesto: el Espíritu gracias a la compenetración de razón y amor devela el misterio del ser humano. 
El estudio riguroso y profundo de la obra teresiana desde la clave de la antropología teológica descubre un proceso pneumatológico. Dicho proceso requiere un criterio de lectura que ordena tripartitamente las dimensiones fundamentales de lo humano y sistematiza el discurso teresiano de acuerdo al designio creador, salvador y consumador.

A continuación se recogen algunos elementos fundamentales que se han ido descubriendo a lo largo del proceso de estudio y elaboración de la tesis doctoral ${ }^{1}$.

El artículo presenta los aspectos introductorios referidos a la obra Castillo Interior y a la metodología de la investigación. Seguidamente, se aborda la antropología de una Teología mística: la sistematización de una antropología latente y la síntesis de la antropología teológica como un itinerario soteriológico desde la creación a la plenificación. Se finaliza con una conclusión.

\section{AsPeCtos INTRODUCtORIOS}

\section{La obra castillo interior}

Teresa escribe sobre sí misma, y desde la experiencia de ser y saberse amada infinitamente por el Señor. Desde la aproximación a la autora, se descubre que su obra Castillo Interior es ella misma entregada a los destinatarios: el último eslabón de su proceso de autocomunicación; su definitiva palabra. Nace así «uno de los libros cimeros de la espiritualidad de la humanidad ${ }^{2}$

1 Estudio patrocinado por la Comisión Nacional de Investigación de Ciencia y Tecnología (CONICYT) del Gobierno de Chile, a través de la beca de doctorado (D21060209) para abordar Una propuesta de antropología teológica en Castillo Interior de Santa Teresa de Ávila, doctora de la Iglesia (1515-1582), presentada y defendida por Agustina Serrano Pérez en la Facultad de Teología de la Pontificia Universidad Católica de Chile, Santiago, para optar al grado de Doctor en Teología Dogmática, bajo la dirección del profesor guía Dr. Juan Noemi Callejas, apoyada por la investigadora Dra. Anneliese Meis Wörmer, corregida por el Dr. Juan Francisco Pinilla Aguilera y supervisada por el experto teresianista Dr. Tomás Álvarez Fernández. La tesis revisada por el Consejo General de la Institución en sesión ordinaria del 15 de marzo del 2011, ha sido aprobada para la publicación en la Serie General, editada por la Institución Gran Duque de Alba, en Ávila (España), encontrándose actualmente en prensa.

2 M. Herráiz, Introducción al Castillo Interior (Burgos 2001) 11. Cf. T. Álvarez, "Introducción a El Castillo interior» en Teresa de Jesús. Doctora de la Iglesia. Obras 
Escribe la obra entre el 2 de junio y el 29 de noviembre de 1577, con significativas interrupciones, pues es redactado en poquísimo tiempo -3 meses aproximadamente- entre sorpresas, viajes, temores y con la sabiduría de la vida. En este tiempo además, vive una de las épocas más complicadas de toda su historia ${ }^{3}$.

Teresa discierne y escribe lo más significativo de su vivencia de Cristo, de la Trinidad, de eclesiología y del misterio del ser humano; ella piensa la experiencia ${ }^{4}$.

El nuevo escrito se sistematiza sobre la base de un símbolo arquitectónico: el castillo, que estructura dándole cohesión y profundidad. Con esto, ella codifica datos de gran valor teológico respecto a su recorrido espiritual que le «sirven de soporte a una síntesis doctrinal»"

Completas (Burgos 51987) 765-786. Cf. J.V. RODRÍGUEZ, «Castillo Interior o Las Moradas» en A. BARRIENTOS, Introducción a la lectura de Santa Teresa de Jesús (Madrid 1978) 311-371.

3 Cf. T. Álvarez, «Nota histórica sobre el autógrafo del Castillo Interior» en T. ÁlvaREZ - A. MAS, Castillo Interior, Santa Teresa de Jesús vol. 2 (Burgos 1990) 239-266. Cf. A. MAs, Teresa de Jesús en el matrimonio espiritual. Un análisis teológico desde las séptimas moradas del Castillo interior (Ávila 1993) 48-62.

4 Cf. M. Herráiz, Introducción al Castillo Interior, 22. Cf. M Pról 1; 4M 1,1.7; M Epíl. 1. Cf. A. MAs, Teresa de Jesús en el matrimonio espiritual. Un análisis teológico desde las séptimas moradas del Castillo interior, 51-54.

5 T. ÁlvareZ, «Nota histórica sobre el autógrafo del Castillo Interior», 241. También para el símbolo del castillo base literaria profana, espiritualidad islámica y sus obras anteriores se pueden consultar los siguientes autores: M. Asín PALACios, «El símil de los castillos y moradas del alma en la mística islámica y en Santa Teresa», AlAndalus 11 (1946) 263-274; R. Richard, "Quelques remarques sur les "Moradas" de Sainte Thérèse», Bulletin Hispanique 47 (1945) 187-198; "Le symbolisme du "Château intérieur" chez Sainte Thérèse», Bulletin Hispanique 67 (1965) 25-41; A. Serrano Plaja, «Una noche toledana. Del Castillo interior al castillo fugitivo. Santa Teresa, Kafka y el Greco», Papeles de Son Armadans 105 (1964) 263-302; VV. AA., "Psicología y Teología en El Castillo Interior», Revista de Espiritualidad 41 (1982) 459-668; A. EGIDO, "La configuración alegórica del Castillo Interior», Boletín del Museo e Instituto Camón Aznar 10 (1983) 69-93; M. GerLI, «El Castillo interior y el Arte de la memoria", Bulletín Hispanique, 86/1-2 (1984) 154-163; L. López-BARALT, «El símbolo de los siete castillos concéntricos del alma en Santa Teresa y el Islam", en Huellas del Islam en la literatura española: de Juan Ruiz a Goytisolo (Madrid 1986) 39-58; J. M. PRIETO, «Los orígenes de la alegoría del Castillo Teresiano», Teresianum 42 (1991) 585-608. 
Ella llama al libro tratado ${ }^{6}$, pues tiene gran contenido temático y persigue la síntesis de tres elementos: la propia autora, el evangelio y un símbolo; es decir, su historia personal, leída desde la Palabra de Dios y concentrada en el símbolo del castillo. La autora pretende el conocimiento de «la vida que vive el hombre en el castillo de sí mismo, y decir la razón teológica de la vida mística» ${ }^{7}$.

Además, el libro trata sobre la acción de Dios: la creación, la salvación y la plenificación. Castillo Interior es la biografía divina, «no trata de cosa, sino de lo que es Élı ${ }^{8}$, y a la luz de Dios se ve el hombre; en Cristo, se revela el ser humano pleno hacia el que avanzamos. Los elementos doctrinales esenciales son Dios y el ser humano, y la relación de personalización que se alcanza en el encuentro?.

El libro se estructura a base de siete moradas: las ascéticas, de la primera a la tercera morada; la de quiebre y paso, la cuarta morada; y las místicas, de la quinta a la séptima morada. La idea o concepto de morada se refiere al estadio en que se da la relación; consiste en la acción de Dios y la respuesta humana. Es importante la distinción, por último, del contenido de la mística de su envoltorio, ya que interesa discernir la gracia «del ropaje en el que viene envuelta» ${ }^{10}$.

\section{M Pról. tít.}

7 T. ÁlvareZ, «Nota histórica sobre el autógrafo del Castillo Interior», 241. También del mismo autor: «Doctrina Espiritual», en Estudios Teresianos, vol. III (Burgos 1996) 465-574; además, Guia al interior del Castillo. Lectura espiritual de las Moradas (Burgos 2000) 314. También cf., M. MarTín Del BlanCo, "Contenido y proceso evolutivo de "Vida", "Camino de Perfección", "Las Moradas"”, Compostellanum 27 (1982) 151-195. Cf. J. CASTELlano, «El Castillo interior de santa Teresa. Presentación y hermenéutica teológica de un libro cumbre de la mística universal», Revista Cistercium 239 (2005) 587-610. Para profundizar en el proceso de interiorización, la recensión de A. Serrano, Teología y Vida 43 (2002) 78-84, sobre J. Welch, Peregrinos espirituales. Carl Jung y Teresa de Jesús (Bilbao 2001) 297. Traducción de María del Carmen Blanco Moreno y Ramón Alfonso Díez Aragón, de Spiritual pilgrims: Carl Jung and Teresa of Avila.

8 Cta 7 dic 77; 209,10.

9 Cf. Martín de Jesús María, «El concepto de alma humana en Las Moradas de Santa Teresa", Revista de Espiritualidad 1 (1942) 203-214. Cf. M. Herráiz, Introducción al Castillo Interior, 37.

10 M. Herráiz, Introducción al Castillo Interior, 41. Cf. T. Álvarez, Guía al interior del Castillo. Lectura espiritual de las Moradas, 5-16; «El futuro de nuestro pasado. Teresa de Jesús y la seducción de los místicos», Monte Carmelo 109 (2001) 35-46; 
Las primeras lectoras de Castillo Interior son las carmelitas, aunque el proyecto era que primero lo vieran los letrados ${ }^{11}$. El primer teólogo que emite un veredicto sobre la obra definitiva es el jesuita Rodrigo Álvarez ${ }^{12}$.

2. La metodología de la investigación

Se ha visto que Teresa, al comunicarse a sí misma en su obra, revela unos ejes articuladores que posibilitan la elaboración de una propuesta antropológica. La sistematización de su comprensión teológica implícita en Castillo Interior se va realizando a través de la escucha de la autora, investigando de qué manera ella responde al misterio del ser humano. Para ello, se usa un método que consiste, fundamentalmente, en una lectura centrada en el texto.

La aproximación al escrito teresiano se realiza desde el minucioso estudio de los términos y teniendo en cuenta la simbología, lo que ayuda a la comprensión de los conceptos antropológicos y permite estructuración tripartita de su antropología teológica ${ }^{13}$, asumiendo el rico significado del espanto ${ }^{14}$.

El anhelo humano de plena humanización se entreteje con el proyecto de divinización por parte de Dios, de tal modo que acontece una búsqueda recíproca: Dios desde dentro del ser humano ilumina todas las moradas para que el ser humano avance a lo recóndito de sí, donde Él mora.

Santa Teresa a contraluz. La Santa ante la crítica (Burgos 2004) 198. También, cf. V. García de la Concha, Al aire de su vuelo (Barcelona 2004) 5-16. Además, cf. M. Martín del Blanco, Santa Teresa de Jesús: Mujer de ayer para el hombre de hoy (Bilbao 1975) 89-112; 189-223; 271-289.

11 Cf. M Epíl. 4: «cuando se os dé a leer -si estuviese para que se vea- después de visto de letrados».

12 Cf. T. Álvarez, «Nota histórica sobre el autógrafo del Castillo Interior», 243.

13 Cf. T. Álvarez, «Simbología teresiana», en Diccionario de Santa Teresa de Jesús (Burgos 2000) 1279-1286; Comentarios a "Vida", "Camino" y "Moradas" de Santa Teresa, (Burgos 2005) 547ss. Cf. R. Rossi, Teresa de Ávila. Biografía de una escritora (Barcelona 1997).

14 Cf. T. Álvarez, "Admiración, estupor, espantar(se). Gesto filosófico en Teresa de Jesús», en Estudios Teresianos, vol. III (Burgos 1996) 313-332. El espanto desemboca en placidez beatificante en el goce de la verdad de Dios. 
El estudio no abarca todo el pensamiento teresiano; más bien se circunscribe al ámbito de una pregunta formulada a través de una hipótesis en la obra clave: Castillo Interior, obra nacida en contexto existencial y vital que decanta su proceso de maduración. En su pensamiento teologal, que ella llama "teología mística», se encuentra su clave hermenéutica para la comunicación de la experiencia. El estilo humilis de sus obras ha sido amplia y ardorosamente discutido ${ }^{15}$.

\section{La antropología de una Teología Mística}

Se es consciente de la complejidad que supone el ofrecimiento de una visión sistemática de un escrito místico -experiencial-; es decir, se sabe y se asume el reto de la sistematización de la antropología teológica en una obra de teología mística (V 10, 1; 11, 5; 12, 5; 18, 2) como la misma autora define su tratado (M Pról. tít). La autora siendo resistente al uso de términos técnicos de teología, los utiliza con la pretensión de hacer comprensible teológicamente la experiencia mística ${ }^{16}$.

15 El debate, respecto al uso o no por parte de la autora del lenguaje popular de Ávila del siglo XVI, continúa siendo actual, véanse los siguientes detalladísimos estudios. Cf. A. Morel-Fatio, «Les lectures de Sainte Thérèse», Bulletin Hispanique 10 (1908) 17-67. Cf. R. Menéndez Pidal, La lengua de Cristóbal Colón, el estilo de Santa Teresa y estudios sobre el siglo XVI (Buenos Aires ${ }^{2}$ 1944) 153; Estudios sobre Santa Teresa, Anejo/19, Edición de José Polo, Málaga, Analecta Malacitana (AnMal), Universidad de Málaga, 1998, 44-73. Cf. F. LÁZARo CARreter, «Santa Teresa de Jesús, escritora. El Libro de la Vida», en T. Egido, Actas del Congreso Internacional Teresiano vol I (Salamanca 1982) 10-27. Cf. N. WATT, «¿Vulgarización intencionada en Santa Teresa? Estudio comparativo de las dos redacciones de Camino de Perfección», Monte Carmelo 92 (1984) 319-346; "El estilo de Santa Teresa en un mundo antifeminista", Monte Carmelo 92/2 (1984) 287-318. Cf. A. Weber, Teresa of Avila and the Rhetoric of Feminity (New Jersey 1990). Cf. V. GARCÍA DE LA CONCHA, "Sermo humilis", coloquialismo y rusticidad en el lenguaje literario teresiano", Monte Carmelo 92/2 (1984) 251-286; El arte literario de Santa Teresa (Barcelona 1981); Al aire de su vuelo.

16 Cf. T. Álvarez, «Nota histórica sobre el autógrafo del Castillo Interior», 241. Cf. S. Ros, «Mística teología», en T. Álvarez, Diccionario de santa Teresa de Jesús (Burgos 2000) 971-1001. 
1. La sistematización de una antropología latente

La antropología latente se descubre conociendo a la autora a través de los términos relevantes fundantes de lo humano y de la simbología que abre al misterio de lo humano y comunica lo inefable ${ }^{17}$.

\subsection{La autora comunica su antropología}

La antropología teresiana se descubre principalmente analizando la idea que la autora tiene de sí misma. Se trata del llamado socratismo teresiano: una no se conoce a sí misma más que a la luz de Dios. Por un lado, Teresa valora mucho la razón, es muy cerebral y no avanza en su reflexión sin entenderse bien a sí misma. En el terreno del amor, desde siempre se ha vivido muy querida: es una mujer emotiva que llega al extremo y lo verbaliza a través del término espanto. La visión teresiana rompe así las fórmulas teológicas desde el espíritu, clave de apertura a la trascendencia desde donde su profecía es de plenitud ${ }^{18}$.

De este modo, la antropología teológica teresiana se expresa a través de la simbología, para completar lo que significan las categorías antropológicas. Se produce un admirable engranaje de símbolo y pensamiento que da el soporte y la graduación a la antropología teresiana, cuya originalidad consiste en que todo lo doctrinal tiene germen experiencial ${ }^{19}$.

17 Los símbolos especialmente relevantes son el castillo y el matrimonio espiritual. Hay otros símbolos funcionales (4M 2,2-6; $5 \mathrm{M}$ 2,2). Además, a los símbolos se unen los vocablos ya citados: razón (conocer, lógica), amor (afectividad, relación), espanto (asombro-admiración-estupor ante el misterio) y espiritu (referido a Dios) proporcionando el esclarecimiento de su visión del ser humano.

18 Las visitas de investigación realizadas a Burgos, Madrid y Ávila (España) han sido de gran ayuda y han posibilitado las entrevistas a expertos teresianistas: T. ÁLVAREZ, M. Herráiz y R. Cuartas. El filósofo hispanista Robert Richard ha tratado muy bien la relación entre los planteamientos del filósofo griego Sócrates con Teresa de Ávila del siglo XVI. Últimamente Juan Manuel, Morilla Delgado, en Conósciti in Me. Itinerario mistico esperienziale in Teresa d'Avila (Milano 2010), en la segunda parte (89-175) presenta un itinerario interior como progreso de conocimiento de sí mismo, aunque para Teresa lo central no es conocerse, sino conocer el misterio, por eso ella escribe «Búscate en Mí».

19 Cf. J. Castellano, «El Castillo interior de santa Teresa. Presentación y hermenéutica teológica de un libro cumbre de la mística universal», 587-610. Cf. C. Cuevas, "El significante alegórico del "Castillo teresiano" ", en VV. AA., Aspectos religiosos y literarios de los escritos de Santa Teresa, Revista Letras de Deusto 12 (1982) 77-97. Cf. F. Márquez Villanueva, «El símil del Castillo interior: sentido y génesis», en 
Teresa explica los tres niveles del proceso místico, y, también, comprensivo: la experiencia, el conocimiento y la comunicación ${ }^{20}$. Es consciente de la graduación del proceso y reconoce la progresividad. La experiencia comporta la percepción y pertenece al ámbito del sentimiento. El conocimiento se halla vinculado a la doctrina, poniendo en juego al pensamiento, al entendimiento. Y la comunicación resulta ser la expresión del convencimiento ${ }^{21}$.

En definitiva, se puede afirmar que «Teresa nunca elaboró un discurso tercero, aunque los presupuestos teológicos implícitos condicionan la interpretación de la obra» ${ }^{22}$.

\subsection{La antropología teresiana desde el texto y más allá del texto}

La antropología implícita se va descubriendo en la lectura del texto teresiano tanto desde la letra impresa como desde el proceso de su vida concreta $y$, aunque interesa el texto explícito, aun es más relevante la obra que el Espíritu hizo en ella: su ser transformado. Se trata de descubrir qué tipo de ser humano es ella. Así, desde la autora, es posible la afirmación: su antropología es ella; ya que se trata de una pneumatología existencial por la muy buena obra que salió en Teresa ${ }^{23}$.

Actas del Congreso Internacional Teresiano II (Salamanca 1982) 495-522. Cf. S. Ros, "El Castillo interior de Santa Teresa. Un libro de caballerías a lo divino», Cántico 30 (1995) 66-71. Cf. V. García De la Concha, El arte literario de Santa Teresa, 228-274. Cf. M. IzQUierdo SorLi, Teresa de Jesús, una aventura interior. Estudio de un simbolo (Ávila 1993). Cf. T. ÁlvareZ, Cultura de mujer en el siglo XVI, 2534. Cf., A. M. Sicari, Nel "Castello Interiore" di Santa Teresa d'Avila. Introdotto da L'inaccessibile castello da Franz Kafka a Santa Teresa (Milano 2006).

20 Cf. M. Martín del Blanco, «Mística y humanismo en Santa Teresa de Jesús», Monte Carmelo 89 (1981) 465-483. Cf. S. Ros, "Mística y siglo XXI: La seducción de los místicos Teresa de Jesús y Juan de la Cruz», Monte Carmelo 109 (2001) 4767; ideas parecidas aborda en «Experiencia y transmisión de la fe con Teresa de Jesús», Revista de Espiritualidad 61 (2002) 231-254.

21 Cf. V 17,5; 23,11.

22 A. MAS, Teresa de Jesús en el matrimonio espiritual. Un análisis teológico desde las séptimas moradas del Castillo interior, 52, la experiencia genera un discurso primero (Vida), se continúa seguido el discurso segundo en Castillo Interior, donde teoriza la experiencia. A lo largo del estudio se va explicitando alguno de los presupuestos mencionados.

23 Cf. R. Cuartas Londoño, «La espiritualidad trinitaria de Santa Teresa de Jesús. La Trinidad: fuente, camino y meta de la vida cristiana», en Revista Cistercium 239 
Su ser mujer cristificada es el testimonio del Espíritu Santo en la fragilidad humana. La antropología teresiana se manifiesta en la acción del Espíritu en su existencia, siendo así ella transparencia de Cristo. De todos modos, la antropología es trinitaria en tanto en cuanto se ve a lo largo de su vida la acción de la Trinidad ${ }^{24}$.

Por lo cual, en ella es posible el descubrimiento de una antropología del exceso: la infinitud en lo finito. La antropología teresiana es altamente positiva porque la imagen de ser humano que refleja está armonizada por la visión y experiencia que tiene de $\operatorname{Dios}^{25}$.

Teresa refleja gran lucidez en la detección, descubrimiento, del misterio del mal que desordena al ser humano y rompe el proyecto relacional de Dios. La autora relativiza lo transitorio y accidental sin ignorarlo, y entiende los males como pasajeros, ya que no se altera el concepto de ser humano revelado en Cristo, en quien el pecado ha sido vencido por amor. Es esta revelación la que explosiona en la séptima morada que presenta al nuevo ser, capaz de contener a Dios y, a la vez, capaz de renegar de sí mismo introduciendo el mal. En definitiva, la persona es misterio, al igual que la realidad divina a cuya imagen está creada, por lo que es capaz de relación con Dios: entra en el misterio trinitario y lo comunica. El ser humano se entrega a Dios porque Dios se ha dado a él. Se trata del misterio circular de las relaciones intratrinitarias ${ }^{26}$.

(2005) 649-661. Del mismo autor Experiencia trinitaria de Santa Teresa de Jesús (Burgos 2004), especialmente las páginas 124-145, que aborda «El singular encuentro con "Los Cartujanos"” y presenta los criterios o indicios de la acción del Espíritu. También las páginas 250-252, hablan del Espíritu que obra en Teresa y posibilita la aceptación de la Palabra; el Espíritu es aposentador y es quien dispone interiormente para la unión; de ese modo el Espíritu configura con Cristo.

24 Cf. Rm 5,5; 8,14. El Espíritu infundido en el creyente crea una nueva conciencia que es fuente de nuevo conocimiento y de nuevo amor $(\mathrm{Rm} 5,5)$ que se manifiesta en la vida del nuevo ser humano $(\mathrm{Rm} 8,14)$. Teresa es muy precavida para no ser acusada de iluminada; porque el tema del Espíritu estaba desterrado en su época; y por eso comunica pocas manifestaciones del Espíritu.

25 Cf. M. Martín del Blanco, «Hacia una teología existencial de la gracia y del pecado en Santa Teresa», Teología espiritual 21 (1977) 185-209. Cf. F. Domínguez Reboiras, «El amor vivo de Dios. Apuntes para una teología de la gracia desde los escritos de Santa Teresa de Jesús», Compostellanum 15 (1970) 5-59; también, «La teología de la gracia en Santa Teresa», Compostellanum 19 (1974) 1-64.

26 Cf. J.M. Martínez de Ilarduia, Perijóresis. Dios, Comunión de personas, modelo de toda comunidad (Vitoria-Gasteiz 2000). 
En Teresa, el autoconocimiento de la grandeza y la miseria es a la luz de Dios y por eso puede vivir como resucitada. La escatología se hace presente en la entraña de la historia, y ella es una persona nueva. Participa de Dios en fe, esperanza y amor, porque Dios la ha encontrado, de tal modo que el ser humano teresiano está capacitado para el acceso al misterio de Dios que acontece en el misterio del hombre.

El dinamismo del conocimiento humano es el don que ya está en nosotros por el Espíritu. La persona se ensancha y dinamiza su capacidad porque el don ya tiene la referencia trinitaria. Desde la séptima morada se vislumbra una antropología trinitaria que, partiendo de la experiencia mística tiñe toda su obra ${ }^{27}$.

\section{La síntesis de una antropología teológica}

El conocimiento de la autora desde el texto y más allá del texto va proporcionando elementos para la sistematización -de alguna manera y no sin dificultades- de un pensamiento antropológico. Planteamiento que trata de «elevarse al plano de la "razón teológica" del hecho místico y de la vida de la gracia ${ }^{28}$.

La antropología teresiana se sustenta en su concepción trinitaria y cristológica y se muestra en la vocación eclesial de comunión y misión. Dicha antropología se basa en la experiencia de una progresiva interrelación entre el conocimiento y el amor que representan la diversidad

27 Cf. M. Herráiz, «Boceto de hombre nuevo según san Juan de la Cruz», en San Juan de la Cruz 10 (1992) 149-165. Cf. J. Ackerman, "El ensanchamiento del alma: la doctrina de san Juan de la Cruz y Santa Teresa de Jesús sobre el efecto de la gracia en el alma», en San Juan de la Cruz 7 (1991) 9-21. Cf. VV. AA., Teresa de Jesuis, mujer, cristiana, maestra (Madrid 1982).

28 T. Álvarez, Comentarios a "Vida", "Camino" y "Moradas" de Santa Teresa, 548. Dice el autor que Teresa, además de dar razón de la experiencia mística, también pretende «diagramar a su modo el proceso de desarrollo de la gracia como vida nueva y misteriosa del creyente [...] fijar el punto de partida de su explicación doctrinal en el hombre: en su capacidad y dignidad, en su hechura a imagen de Dios, en su condición de templo del Espíritu, en su vocación radical a la comunión con Dios [...] relación con Dios que pasa necesariamente por Cristo [...]. El cristiano que [...] vive a fondo la inhabitación trinitaria, [...] llegará a la plenitud [que] revierte [...] en hacer Iglesia» (548-549). Comentario parecido en T. Álvarez, «Nota histórica sobre el autógrafo del Castillo Interior», 241. 
de la realidad humana. El centro es la persona divina que unifica al ser humano que se va conformando con Cristo ${ }^{29}$.

La configuración cristológica se expresa en una interiorización contemplativa y una entrega comprometida que encarna la presencia trinitaria en el mundo. Se trata de la sabiduría interior y el amor entregado. Para Teresa «;Gran cosa es el saber y las letras para todo! ${ }^{30}$.

Y además del gran valor otorgado al pensamiento, la autora subraya que el amor es fundamental: "no está la cosa en pensar mucho, sino en amar mucho; $y[. .$.$] en la mayor determinación de desear contentar en todo$ a Dios y procurar [...] que vaya siempre adelante la honra y gloria de su Hijo y el aumento de la Iglesia católica....1 ${ }^{31}$.

Teresa describe la profunda vivencia con Cristo y experimenta la permanente presencia trinitaria. La imagen del matrimonio espiritual vehiculiza la relación entre el ser humano y Dios. De ese modo, el servicio eclesial nace de la cristología y de su concepción trinitaria, lo que se manifiesta en su conciencia y en su práctica de compromiso responsable. Para Teresa lo fundamental es la relación interpersonal del ser humano con el otro y con Dios: «nunca se fueron de con ella» ${ }^{32}$.

La antropología teresiana muestra la vocación del hombre a la unión con Dios. Deseo teresiano que solo se recibe como don de Dios y que a ella le costó comprender. Por eso, su propuesta consiste en un recorrido inédito que va revelando la dignidad humana junto a la realidad del pecado, desde la primera hasta la última morada. Se propone así un itinerario antropológico de acceso al misterio de Dios en la hondura humana del Castillo Interior. Aquí es donde cada persona va siendo transfigurada a imagen de Cristo, quien sigue convocando a una comunidad eclesial fraterna y solidaria alimentada por el Espíritu que va posibilitando el reinado del Padre por el Hijo en la historia humana ${ }^{33}$.

29 Cf. 1 M 1, 1. Cristo es el Amado que goza y se deleita con ella. En V 19,15, presenta un Dios que la espera y se dona siempre; un Dios, que nunca falta (V 25, 17).

$30 \quad 4 \mathrm{M} 1,5$.

$31 \quad 4 \mathrm{M} 1,7$.

$327 \mathrm{M} 1,6$.

33 Cf. T. Álvarez, Comentarios a "Vida", "Camino" y "Moradas" de Santa Teresa, 549. Dice el autor: «el hombre por Cristo a la Trinidad para la Iglesia». Así cada persona se abre a la vivencia de una existencia bajo el influjo transformante de la gracia. De 
El pensamiento teresiano sobre lo humano se puede sintetizar desde la luz que irradia el punto de llegada ${ }^{34}$. Los cuatro capítulos de la séptima morada expresan el culmen de la experiencia humana ${ }^{35}$.

El ser humano experimenta, lo que sabe y cree por fe, a Dios uno y trino. Así lo expresa Teresa: «por visión intelectual [...] se le muestra la Santísima Trinidad, todas tres personas [...] distintas, [...] y un solo Dios, de manera que lo que tenemos por fe, allí lo entiende el alma, [...], y la dan a entender [...] que vendría Él y el Padre y el Espíritu Santo a morar con el alma que le ama y guarda sus mandamientos (Jn 14,23)»36.

El segundo capítulo de la séptima morada refleja el encuentro del ser humano con Jesucristo: «se le representó el Señor [...], como después de resucitado, y le dijo que [...] sus cosas tomase ella por suyas, y él tendría cuidado de las suyas ${ }^{37}$. Además, el encuentro se va profundizando: «El que se arrima y allega a Dios hácese un espíritu con El [...] su vida es ya Cristo ${ }^{38}$. Y el ser humano se experimenta fundamentado en Cristo, lo que Teresa expresa con la siguiente imagen: YY esto se entiende [...] claro [...] ser Dios el que da vida a nuestra alma [...] ¡oh vida de mi vida y sustento que me sustentas! [...] de aquellos pechos divinos [...] sustentando el alma, salen unos rayos de leche» ${ }^{39}$.

Así, es posible para la persona una vida en Cristo y un paso a la proexistencia. Dice en el capítulo tercero de la séptima morada: «lo que más me espanta de todo [...] el deseo que tienen de servirle [...] no solo no desean morirse, mas vivir muchos años padeciendo [...] no desea verse en ella [la gloria]; su gloria tiene puesta en si pudiesen ayudar en algo al

modo poético Teresa dirá «que es mi Amado para mí, y yo soy para mi Amado» en la Poesía 2, Santa Teresa de Jesús, Obras completas (Madrid ${ }^{2}$ 1976) 1266.

34 Cf. A. Mas, Teresa de Jesús en el matrimonio espiritual. Un análisis teológico desde las séptimas moradas del Castillo interior, 457. Cf. J. CASTELLANO, "El Castillo interior de santa Teresa. Presentación y hermenéutica teológica de un libro cumbre de la mística universal», 587-610; y cf. M. IzQUIERdo SORLI, Teresa de Jesús. Con los pies descalzos (Madrid 2006) 17-21.

35 Cf. T. Álvarez, Guia al interior del Castillo. Lectura espiritual de las Moradas, 266-312.

$367 \mathrm{M} \mathrm{1,6.}$

37 7M 2, 1.

$387 \mathrm{M} \mathrm{2,} 5$.

39 $7 \mathrm{M} \mathrm{2,6.}$ 
Crucificado» ${ }^{40}$. Y, la autora continúa: «los deseos de gozar de Dios y salir de este destierro [...] y mira en sí misma con la continuanza que le tiene consigo, y con aquello se contenta y ofrece» ${ }^{41}$.

Ese vivir para otros se traduce en un compromiso esponsal que se empeña en la plenitud para todos. Dice Teresa en el último capítulo de la última morada: "Para esto es la oración, hijas mías; de esto sirve este matrimonio espiritual; de que nazcan obras, obras» ${ }^{42}$. La práctica transformadora será posible si se sigue su consejo: «Poned los ojos en el crucificado y haráseos todo poco» ${ }^{43}$. El ser humano que se confía a Dios experimenta su misericordia, amor que Teresa formula así: «El Señor no mira tanto la grandeza de las obras como el amor con que se hacen [...] pudiendo cada día más y más» ${ }^{44}$.

Teresa termina su obra a los 63 años invitando a la transformación de los deseos en compromiso, aconsejando el proceso por las siete moradas. El Castillo Interior es la biografía de todos y cada uno de nosotros en la que se refleja la acción de Dios ${ }^{45}$.

Desde la unión plena, experiencia que ilumina el camino, se detecta una posible propuesta antropológica, gracias a la cual el ser humano es llamado a la experiencia de interioridad, de comunitariedad y de compromiso; es un ser creado para plenificarse a través de la historia ${ }^{46}$.

De tal manera que es posible una sistematización de los elementos antropológicos descubiertos a través de la relectura de la hipótesis en la perspectiva de la creación, la salvación y la consumación ${ }^{47}$.

$7 \mathrm{M} \mathrm{3,6.}$

$417 \mathrm{M} \mathrm{3,} 7$.

$427 \mathrm{M} \mathrm{4}, 6$.

$437 \mathrm{M} \mathrm{4}, 8$.

$447 \mathrm{M} \mathrm{4,15.}$

45 Cf. A. MAs, Acercar el cielo. Itinerario espiritual con Teresa de Jesús (Santander 2004) 246-279. Cf. M. Herráiz, Introducción al Castillo Interior, 124-137.

46 Cf. M Epíl. 4. En la primera morada se reza vocalmente; en las tres siguientes se conoce la humanidad de Jesucristo; en la quinta se asume la cruz para que en las dos últimas se perfeccione el amor, se medite la Palabra y se viva la contemplación. También Cf. Ideario Adsis 2.3 (donde se aborda la vocación de presencia contemplativa y encarnada.

47 Cf. A. Serrano, Una propuesta de Antropología Teológica en Castillo Interior de Santa Teresa de Avila, doctora de la Iglesia (1515-1582), Tesis doctoral en Teología 


\subsection{La creación amada}

La antropología teológica latente en Castillo Interior se ha ido haciendo patente a través de la hipótesis leída en clave de creación. El supuesto es que el espiritu de Dios desde la compenetración de amor y razón devela el misterio asombroso y sobrecogedor (espanto) de la criatura humana ${ }^{48}$.

La identidad y la libertad se han ido configurando desde el proceso de búsqueda del ser humano que pretende el descubrimiento del misterio creador. La persona puede conocerse acudiendo al origen de su ser que, para Teresa, está en el Dios-Amor que da la existencia.

La criatura se constituye como fruto del amor divino que regala la libertad para la autorrealización y la madurez desde la experiencia primigenia de gratuidad. Al ser humano, además del origen, le interesa conocer el fin, el para qué ha sido creado.

La autora expresa que, a través de la historia de salvación, el ser humano culminará en el amor de Dios. La meta, por tanto, es el mismo seno de Dios trinitario, al que se accede, por gracia, a través de una opción de amor razonada, gracias a la racionalidad amorosa.

La criatura va descubriendo el misterio de sí misma a lo largo del itinerario procesual desde el origen, amor de Dios, hacia la meta, amor de Dios. El encuentro crea asombro y sobrecogimiento, espanto, cuando descubre que la finitud es su identidad y cuando va atisbando el significado del misterio de su procedencia y de su finalidad. El ser humano va experimentando el misterio -identidad del sujeto libre cuyo origen y fin es el amor-como salvación en la historia concreta.

El ser creado libre busca su identidad en el origen y en la meta de su existencia, es decir, en el seno amoroso de Dios trinitario. Además, puede conocer y amar el misterio con asombro y sobrecogimiento. Todo ello gracias al espiritu de Dios que se hace presente gestando la creación amada.

Es decir, en el Espíritu el Padre crea por el Hijo dando la existencia a lo que no era en un tiempo y en un espacio. La donación gratuita de la

Dogmática (Santiago de Chile 2009), Biblioteca de la Facultad de Teología de la Pontificia Universidad Católica de Chile. A este estudio me referiré frecuentemente en las notas siguientes.

$48 \mathrm{Ib}, 35-81$. 
vida puede ser experimentada, entendida y comunicada como el primer acontecimiento salvador hacia la plenitud ${ }^{49}$.

\subsection{La soteriología como salvación transformadora}

A continuación se va expresando la antropología teológica teresiana en perspectiva soteriológica como salvación transformadora. Así la hipótesis considera que el espiritu del Señor desde la compenetración de amor y razón devela el misterio que admira y desafía (espanta) al ser humano ${ }^{50}$.

La posibilidad de la relación humano-divina despliega un ser humano que, aceptando la relatividad de su conocimiento y abriéndose con progresividad al misterio de la salvación, puede ir siendo copartícipe del plan soteriológico.

El sujeto se va comprendiendo como alteridad del amor divino a través del seguimiento de Jesús. En el proceso se descubre a Jesucristo como el único y auténtico mediador que salva. La salvación ofrecida consiste en la filiación y la fraternidad para solidarizarse en la liberación del pecado. La vivencia soteriológica es posible gracias al encuentro con el resucitado que comunica el futuro aconteciendo en la historia.

Así resulta que la experiencia de la salvación transformadora va logrando la compenetración de amor y razón, la unidad en la pluralidad de lo humano. Gracias a la relación Dios y hombre, cumplida a cabalidad en Cristo, todo ser humano puede, rebasándose, abrirse a la divinización. El camino no depende exclusivamente del propio esfuerzo sino que, sobre todo, es don divino que expresa la eficacia y la fecundidad del conocimiento amoroso.

De ese modo se plantea la posibilidad de aproximarse a la particularidad del ser humano que es cuerpo y alma, que se muestra como varón y mujer, y es capaz del establecimiento de relaciones en un mundo concre-

49 Cf. J. Noemi, El mundo, creación y promesa de Dios (Santiago de Chile 1996), 16. Cf. L.M. Armendáriz, Hombre y mundo a la luz del creador (Madrid 2001). También puede resultar interesante en perspectiva de espiritualidad y de divulgación: Cf. R. Berzosa, 100 preguntas sobre el misterio de nuestros orígenes. Antropología en clave cristiana (Burgos 2005).

50 Cf., A. Serrano, Una propuesta de antropología teológica en Castillo Interior de Santa Teresa de Ávila, doctora de la Iglesia (1515-1582), 82-187. 
to. La persona experimenta la admiración y el desafío ante la posibilidad de la comunicación a otros del plan divino de progresiva salvación.

Finalmente, se muestra la identidad peculiar de lo humano: siendo temporal y mundano, se va forjando como sujeto libre y responsable, capaz de transcendencia y de reconocerse alteridad de Dios, gracias al espiritu del Señor.

El ser humano va conociendo relativa y procesualmente el misterio en la relación con Dios que le capacita para el protagonismo en la salvación. La clave es el amor encarnado en la persona de Cristo que realiza en plenitud esta relación dialogal y que, por el seguimiento de Jesús, la mediación que Él realiza y el encuentro con el resucitado, va conduciendo al ser humano hacia la plenitud. Y, aunque el espanto permanece, la persona descubre cómo la historia va siendo conducida a plenitud por el espiritu del Señor que continúa estando presente activamente en el tiempo y el mundo.

El misterio salvador se revela en Cristo quien es la plena realización del designio divino. Por eso, la antropología teresiana es cristología implícita; es decir, se necesita un ser humano que se pueda pensar desde la encarnación de Dios, que sea receptividad activa -como el Hijo que recibe del Padre y el Espíritu- en mutua interdependencia ${ }^{51}$.

\subsection{La escatología como plenitud unificadora}

Finalmente, se sistematizan algunos contenidos teológicos que no siempre aparecen nítidamente tratados, sino que, más bien, se presentan únicamente evocados y sugeridos y siempre abiertos a ulteriores profundizaciones y formulaciones. La antropología teológica escatológica se puede formular como plenitud unificadora gracias al único proceso

51 Cf. A. MeIs, «El Rostro del Otro: Acercamiento recientes a la Antropología Teológica», Teología y Vida 39 (1998) 13-38; "La Gracia, ¿Verdad teológica en crisis?», Teología y Vida 31 (1990) 227-255. Cf. L. LADARIA, Teología del pecado original y de la gracia (Madrid 1993); Introducción a la Antropología Teológica (Estella-Navarra 1996). Puede aportar elementos para la reflexión, Cf. E. STEIN, La estructura de la persona humana (Madrid 2003). Traducido por José Mardomingo, del original alemán Der aufbau der menschlichen person, 1994; E. STEIN, El Castillo Interior, en Obras Completas, vol. V (Burgos) 79-106. También, M. Herrárz, Discernimiento espiritual en Teresa y Juan de la Cruz (Frontera Hegian 64), (Vitoria-Gazteiz 2008). 
en su triple dimensión. La plenitud se aborda desde el supuesto en que el Espiritu Santo desde la compenetración de amor y razón desvanece el estupor y pavor del ser humano ante el misterio que va develándose ${ }^{52}$.

El ser humano desde el conocimiento puede abrirse a la comprensión de la plenitud unificadora entendida como la meta y como el rebosamiento del proceso soteriológico iniciado en la creación amada. Es decir, se descubre, entiende y contempla al ser humano desde la divinización, o sea, se ve la cristificación a la que va llegando la historia. Así, en los textos de Teresa, se descubre que el misterio del ser humano se revela en el Dios que, habitando lo humano, amplifica el conocimiento.

El ensanchamiento remite al amor que vislumbra a Dios cuando se entra en el ámbito de la presencia divina, en la cual la persona va unificándose en la medida que la voluntad de Dios es su única pretensión.

El itinerario de progresiva compenetración de la razón y el amor va conduciendo a la plenitud unificadora, meta que da sentido a la existencia. Desde el final positivo se contempla el proceso, porque es Dios mismo quien garantiza el encuentro definitivo con Él.

De tal modo que se ofrece la posibilidad del cara a cara con Dios, que desvanece el estupor y pavor del ser humano, donde la escatología es la conclusión que completa la antropología.

Será el Espíritu Santo quien estando presente -trascendencia encarnada- va comunicando al Dios trino hasta la plenificación total. El sujeto, por gracia, se abre a una vida nueva esperando el cumplimiento de la promesa.

En definitiva, la persona va atisbando su misterio en Dios y descubre con gozo que el final es de plenitud. Así, lo definitivo ilumina el sentido de la existencia desde la experiencia del amor de Dios. Él mismo se encarga de que el ser humano pueda libremente implicarse en el proceso para el develamiento del misterio y posibilita que el espanto se disipe «ya sí, pero todavía no" totalmente. Se puede vivir en el presente el futuro, y así se experimenta la salvación y, a la vez, se aguarda su plenitud, pues aun no se ha consumado. Por eso, el sujeto libre espera confiadamente un desenlace positivo gracias al Espiritu Santo.

52 Cf. A. Serrano, Una propuesta de antropología teológica en Castillo Interior de Santa Teresa de Ávila, doctora de la Iglesia (1515-1582), 188-243. 
La iniciativa y la conclusión son de Dios, quien sostiene la finitud humana y va guiando la libertad para la acogida de la inhabitación trinitaria ${ }^{53}$.

\section{CONCLUSIÓN}

1. La antropología teresiana, pneumatológica, unitaria y de misterio, presenta el espanto de lo humano develándose en lo trinitario. Así el enigma humano se esclarece ante la sabiduría amorosa del Espíritu. La hipótesis se transforma en tesis gracias a lo descubierto en el texto teresiano sobre la relación entre Dios y el ser humano ${ }^{54}$.

La obra teresiana va poniendo de manifiesto la donación de Dios como el fundamento trascendental de lo humano, lo que genera asombro y sobrecogimiento ante el misterio del origen y del fin. Ambos, el principio y la consumación, se entienden en interacción; debido a que la creación se contempla como hecho salvífico desde el proceso en el que todo lo creado está orientado a la nueva creación. La creación se sigue gestando hoy y se van descubriendo temas antropológicos que actualmente son debatidos. Teresa nos invita a pensar la receptividad como la mayor actividad a que el ser humano es convocado por el Espíritu Santo, lo que sucede cuando la finitud acoge la infinitud, lo inesperado de Dios. Asimismo, la relación entre el conocimiento y el amor va generando la libertad inteligente y amorosa; también se presenta la libertad en vinculación con la gratuidad; y, por último, libertad regalada, como don divino, se plasma en el amor sabio. Teresa utiliza el término espanto para sugerir una posible propuesta de antropología enriquecida con lo divino.

La relación de Dios y el ser humano es posible y se ha realizado en la historia en Jesucristo. La encarnación revela la viabilidad de un ser humano que se vaya configurando como sujeto personal, como misterio que admira y desafía, porque la compleja finitud es conducida hacia la

53 Cf. J. Noemi, Esperanza en busca de Inteligencia. Atisbos teológicos (Santiago 2005) 46-49. Cf. J.L. Ruiz de la PeÑa, La Pascua de la creación. Escatología (Madrid 1996). También, C. AleXandre, Ser místico. En la Escuela de Teresa de Ávila y Juan de la Cruz (Burgos 2008); M. Reus - F.J. Vitoria CormenZana, Experiencia y gratuidad. La fe cristiana (Madrid 2010).

54 Cf. A. Serrano, Una propuesta de antropología teológica en Castillo Interior de Santa Teresa de Avila, doctora de la Iglesia (1515-1582), 263-265. 
divinización. La salvación sigue aconteciendo hoy y sigue siendo discutido el problema del mal, que en Teresa es el pecado. Al ser humano le cuesta la fragilidad pero es el camino para vencer el pecado, como en Jesús que siendo crucificado (víctima) resucita. Otros contenidos relevantes y significativos para hoy, desde la razón y el amor, son: la alteridad, la presencia y la gratitud. Finalmente, Teresa propone una antropología transformadora desde lo tremendo y lo fascinante de la complejidad humana.

La plenitud del hombre a través de la unión con Dios es punto de llegada de la creación soteriológica y supone el cumplimiento de la antropología. La historia puede ser tiempo de salvación para cada existencia que espera la manifestación de lo definitivo; cumplimiento de la promesa que se va experimentando en la comunidad eclesial donde se vive la dimensión profética y mística. La plenitud teresiana ilumina todo el proceso lo que ayuda a profundizar y a asumir diversos cuestionamientos. La definitividad resulta cada día más costosa, en un mundo donde todo es provisional y pasajero, donde todo tiene fecha de caducidad y se vota; es difícil vivir compromisos de por vida. Frente a ello Teresa sigue proponiendo la aproximación de lo último, la resurrección. Además, referidos a la razón y el amor, se presentan las explicaciones de la plenitud, la desmesura-exceso y el final positivo. Termina Teresa proponiendo una antropología posibilitadora, es decir integradora de toda la existencia humana.

La sabiduría amorosa del Espíritu va generando en cada creyente el crecimiento en la experiencia de Dios, de los hermanos y del servicio, vivencia de la interioridad, de la comunitariedad y del compromiso. En Teresa, la mística consiste en la experiencia de lo que se cree por fe; se trata de la aproximación de lo escatológico a la historia individual y comunitaria. Es la vivencia de lo sagrado en espacios y tiempos determinados en los que se armoniza pasado, presente y futuro; esto, finalmente, forma parte de la vivencia sacramental.

El ser humano puede comprender su misterio vivencialmente en Dios. Dice Teresa que la creatura nueva manifiesta «el deseo que queda en estas almas de que se haga la voluntad de Dios en ellas, que todo lo que su Majestad hace tienen por bueno: si quisiere que padezca, enhorabuena; si no, no se mata como solía ${ }^{55}$.

7M 3, 4 . 
2. La antropología es una ciencia de actualidad que se proyecta al futuro. Así, hay realidades que interrogan al varón y a la mujer de hoy en un contexto de división y negatividad, pecado, urgido de gracia. De tal modo que la latente antropología teresiana ha ido saliendo a la luz invitando a la reflexión sobre la receptividad, lo femenino y el misterio.

Desde el Espíritu Santo lo definitivo (escatología) puede ir siendo acogido gracias a la receptividad (creación), presente en la fragilidad del ser humano (salvación). Es decir que la creatura divina, varón y mujer, puede abrirse a la plenitud del Espíritu Santo que habita en el ser humano.

Desde el ser humano, inteligente y amoroso, la plenitud (escatología) va dando luz a lo femenino (creación) entendido en la perspectiva de la alteridad (salvación). Es decir, la alteridad, el otro dando identidad, revela el valor de lo femenino y masculino, en el proceso hacia la plena humanización.

Desde el espanto se posibilita (escatología) la transformación (creación) en camino hacia la unidad (salvación). Es decir, el proyecto único de Dios-amor requiere la integración que transformando todo lo recibido (lo creado) vaya posibilitando la aproximación al misterio tremendo y fascinante (espanto, asombro, admiración, estupor).

Cada tema se correlaciona con otras áreas que requieren ser abordados para la formulación adecuada de las preguntas acuciantes del hombre actual. En la búsqueda, se trata de encontrar respuestas dadoras de sentido. Teresa sigue teniendo una palabra que aportar, y así finaliza su obra: «Para esto es la oración, hijas mías; de esto sirve este matrimonio espiritual: de que nazcan siempre obras, obras [...] y me dé gracia para que yo obre algo de lo que os digo ${ }^{56}$.

$567 \mathrm{M} \mathrm{4,} 6$ y 16. 
Resumen: El artículo presenta a Santa Teresa de Ávila (1515-1582) en un contexto histórico marcado por la apertura y el resurgimiento teológico, junto con un giro a posturas rígidas. En ese tiempo ella funda 17 conventos y escribe todas sus obras. Castillo Interior es el último eslabón de su proceso de autocomunicación, en que codifica su pensamiento teológico, estructurado en siete moradas que dan cuenta de la relación entre Dios y la respuesta humana.

Este trabajo muestra la antropología de una Teología mística, como la autora define su obra Castillo Interior, y trata de sintetizar la antropología teológica teresiana como un proceso salvífico desde el origen hasta la consumación. Finalmente se ofrecen unos rasgos característicos de la antropología teresiana en la que el misterio del ser humano se esclarece en Dios trinitario, es decir en la sabiduría amorosa del Espíritu.

Palabras clave: antropología, misterio, conocimiento,sabiduría amorosa.

Abstract: The a presents Saint Teresa of Ávila (1515-1582) in an historical context marked by theological resurgence and opening, together with a shift to rigid positions. In this period, she founds 17 convents and writes all her work. Interior Castle is the last link in her process of self-communication, and in which she encodes her theological thinking, structured in seven mansions that account for the relationship between God and the human response.

This work shows the anthropology of a Mystical theology, as the author defines her work Interior Castle, and tries to synthesize Teresian theological anthropology as a salvific process from origin to consummation. Finally, the articles gives some characteristic features of Teresian anthropology, in which the mystery of human beings is illuminated in the Trinitarian God, i.e., in the loving wisdom of the Spirit.

Keywords: anthropology, mystery, knowledge, loving wisdom. 